J. Lake Sci. (湖泊科学), 2019, 31(2): 345-354

DOI 10. 18307/2019. 0204

(c) 2019 by Journal of Lake Sciences

\title{
基于通径分析法的太湖蓝藻水华定量气象评估模型”
}

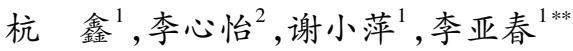 \\ ( 1 : 江苏省气象服务中心, 南京 210008) \\ (2:南京信息工程大学应用气象学院,南京 210044)
}

\begin{abstract}
摘 要: 利用 2005-2017 年太湖周边区域气象观测资料和基于遥感解译的蓝藻水华信息,基于信息量权数法构建太湖 蓝藻水华影响程度指数 (简称为蓝藻指数), 应用通径分析法, 分析年平均气温 $\left(T_{\mathrm{y}}\right) 、 1-3$ 月平均气温 $\left(T_{1-3}\right)$ 、年降水量 $\left(R_{\mathrm{y}}\right) 、 6-7$ 月降水量 $\left(R_{6-7}\right)$ 和年高温日数 $\left(D_{\mathrm{T} \text { max }}\right) 5$ 个气象因子对蓝藻水华影响的直接效应和间接效应, 在此基础上构 建太湖蓝藻水华气象评估模型. 结果表明, 2007 年蓝藻指数值最大, 为 $0.759,2017$ 年其次, 为 $0.709,2009$ 年最小, 仅为 0.113 , 蓝藻指数与实际情况基本相符; 直接通径系数中 $T_{\mathrm{y}}$ 和 $T_{1-3}$ 为正值, 其余为负值, 表明 $T_{\mathrm{y}}$ 和 $T_{1-3}$ 对蓝藻水华的发生发 展具有正效应, 而 $R_{\mathrm{y}} 、 R_{6-7}$ 和 $D_{\mathrm{T} \max }$ 具有负效应, 总通径系数绝对值排序为: $T_{\mathrm{y}}>T_{1-3}>R_{\mathrm{y}}>R_{6-7}>D_{\mathrm{T} \max }$, 由此可以反映各气 象因子对蓝藻水华影响程度的权重. 根据模型计算的综合气象指数与蓝藻指数之间的相关系数达 0.826 , 通过 0.01 显著 性检验, 根据百分位法将蓝藻指数和气象指数进行等级划分, 分类总精度为 $84.6 \%$, 其中中度以上达 $90.9 \%$, 表明模型能 够较好地反映综合气象因子与蓝藻水华发生发展程度的关系, 在水体富营养化程度没有明显改善的情况下, 可用于太湖 蓝藻水华定量气象评估. 上述研究结果有助于更好地理解环境因子、尤其是气象因子在蓝藻生长和水华形成机制中所起 的作用,从而为太湖蓝藻水华的监测、预测预警和精细化防控提供理论依据.
\end{abstract}

关键词: 蓝藻水华;卫星遥感; 通径分析;气象评估;太湖

\section{The quantitative meteorological evaluation model of cyanobacterial bloom in Lake Taihu based on path analysis}

\author{
HANG Xin $^{1}$, LI Xinyi ${ }^{2}$, XIE Xiaoping ${ }^{1} \&$ LI Yachun $^{1 * *}$ \\ (1: Jiangsu Meteorological Service Center, Nanjing 210008, P.R.China) \\ (2: Nanjing University of Science and Technology, School of Applied Meteorology, Nanjing 210044, P.R.China)
}

Abstract: Based on the meteorological data and satellite imageries of Lake Taihu and surrounding areas from 2005 to 2017 , the paper built a cyanobacterial bloom index according to the information weight method, and analyzed the direct and indirect effects of cyanobacterial bloom from 5 meteorological factors (the annual average temperature $\left(T_{\mathrm{y}}\right)$, the average temperature from January to $\operatorname{March}\left(T_{1-3}\right)$, the annual precipitation $\left(R_{\mathrm{y}}\right)$, the precipitation from June to July $\left(R_{6-7}\right)$, the annual high temperature days $\left(D_{\text {Tmax }}\right)$ based on path analysis. The meteorological evaluation model of cyanobacterial bloom was built on this basis. The results show that the cyanobacterial bloom index of 2007 is the biggest $(0.759), 2017$ is the second $(0.709), 2009$ is the lowest $(0.113)$. The cyanobacterial bloom index is basically consistent with the actual situation. $T_{y}$ and $T_{1-3}$ from direct path coefficient is positive, the rest is negative, it showed that $T_{\mathrm{y}}$ and $T_{1-3}$ have positive effect on the occurrence and development of cyanobacteria bloom, however, the rest have the negative effect. The ordering of the absolute value of the total path coefficient is: $T_{\mathrm{y}}>T_{1-3}>R_{\mathrm{y}}>$ $R_{6-7}>D_{\text {Tmax }}$, this can reflect the weight of meteorological factors affecting cyanobacteria bloom. According to this model, the correlation coefficient between the cyanobacterial bloom index and the comprehensive meteorological index passed 0.01 significance test. Then we ranked the cyanobacterial bloom index and meteorological factors according to percentile method. The total classification accuracy was $84.6 \%$, and the moderate above it come up to $90.9 \%$. It showed that the model can reflect the relationship between

* 江苏省基础研究计划太湖专项( BK2007745)、江苏省科技支撑计划项目 (BE2011840) 和江苏省气象局重点项目 ( KZ201403) 联合资助. 2018-06-22 收稿; 2018-09-05 收修改稿. 杭金金 (1990 ), 男, 硕士, 工程师; E-mail: 570702005@ qq.com.

** 通信作者; E-mail: jsqxlyc@163.com. 
the comprehensive meteorological factors and the occurrence and development of cyanobacteria bloom better, so it can be used in the quantitative meteorological evaluation of cyanobacteria bloom in Lake Taihu under the circumstances of eutrophication degree without significant improvement. The research above help to better understand the role of environmental factors, especially meteorological factors, in the formation mechanism of cyanobacterial bloom, and provide the basis for the prediction, early warning and fine prevention \& control of cyanobacteria bloom in Lake Taihu.

Keywords: Cyanobacterial bloom; remote sensing; path analysis ; meteorological evaluation; Lake Taihu

湖泊污染及由此带来的富营养化是目前中国淡水湖泊面临的主要生态环境问题, 其直接后果就是蓝藻 水华的频繁暴发 ${ }^{[-3]}$. 蓝藻是淡水湖泊中比较常见的浮游植物种类, 在适宜的气象条件和营养盐浓度下, 就 会暴发性的生长, 形成蓝藻水华 ${ }^{[4-6]}$. 气候变化和水质富营养化被认为是近几十年来太湖蓝藻水华增多趋重 的两个重要原因 ${ }^{[7-10]}$. 孔繁翔等 ${ }^{[11-13]}$ 研究发现太湖底泥中的内源营养盐足以支撑蓝藻的生长, 营养盐条件 已经不是太湖蓝藻生长的限制因子,气象条件可能成为其主要限制因子.

现有研究已经证实,气温、风、光照、降水等气象因子都会对太湖蓝藻的生长和水华的形成产生重要的 影响 ${ }^{[14-17]}$, 而不同的气象因子及其在蓝藻生长和水华形成的不同阶段所起的作用也明显不同. 秦伯强 等 ${ }^{[18-19]}$ 研究发现, 在蓝藻细胞生长阶段, 营养盐、温度、光照等环境因素决定了蓝藻生物量的多少, 为蓝藻水 华 “暴发” 积累了物质基础, 在蓝藻水华暴发阶段, 在风浪作用下, 蓝藻细胞 (团) 浮力作用与水动力湍流作 用的共同影响决定了蓝藻水华的规模、范围及位置. 李亚春等 ${ }^{[20]}$ 研究表明气温并非复苏后太湖蓝藻水华出 现与否的主要限制因子, 适度高温有利于蓝藻水华形成. 张海春等 ${ }^{[21]}$ 通过水柱试验发现充足的日照是蓝藻 水华暴发的条件之一, 但并非必要条件. 还有一些学者 ${ }^{[22-24]}$ 利用气象与卫星观测数据, 并结合 WRF 模式, 研 究认为微风有利于太湖蓝藻水华聚集, 静风和大风则会产生抑制作用, 风向则主要影响蓝藻水华在太湖的 空间分布格局. 在降水方面, 有研究认为, 持续大量的降水会产生扰动和稀释作用, 不利于蓝藻成群上浮形 成水华 ${ }^{[25]}$, 但降水的这种抑制作用是阶段性的 ${ }^{[26]}$. 也有研究认为当降水量增加时, 地表径流增多, 将沿岸农 田土壤中的化学物质带人湖水, 中长期内增加湖水营养盐和污染物, 促进蓝藻水华的发生 ${ }^{[27-28]}$. 这些研究成 果, 进一步明确了气象条件对蓝藻生长和水华形成具有重要作用, 但大都是分析单个因子对蓝藻水华的影 响, 有些甚至只是定性分析, 因此综合考虑多气象因子并定量评估这些气象因子的影响, 显然有助于更好地 理解环境因子、尤其是气象因子在蓝藻生长和水华形成机制中所起的作用.

为此,本文利用 2005-2017 年太湖周边区域气象观测资料和年蓝藻水华面积与频次信息, 基于通径分 析法分析各气象因子对蓝藻水华影响的直接效应和间接效应, 在此基础上构建太湖蓝藻水华气象评估模 型, 定量评估气象条件对蓝藻水华的综合影响, 为太湖蓝藻水华的监测、预测预警和精细化防控提供依据.

\section{1 数据与方法}

\section{1 数据介绍}

气象观测资料来源于江苏省气象局, 主要选用太湖周边区域无锡、宜兴、苏州、吴江、东山 5 个基本站 2005-2017 年的日平均气温、日最高气温、日日照时数、日降水量和日平均风速观测资料.

卫星资料来源于国家卫星气象中心和江苏省气象局, 选用 EOS/MODIS 卫星的 Terra/Aqua 传感器和 FY-3 卫星的 MERSI 传感器观测的影像数据, 空间分辨率均为 $250 \mathrm{~m}$.

\section{2 太湖蓝藻水华的遥感反演方法}

由于覆盖蓝藻水华的湖面与清洁的湖面在可见光和近红外波段都有较为明显的差异 ${ }^{[29]}$, 尤其是在近红 外波段, 其反射率明显高于无藻的水体, 因此衍生了多种蓝藻水华卫星反演模型, 包括波段差值、波段比值、 归一化植被指数 $(N D V I)$ 及藻类指数等模型 ${ }^{[30-32]}$. 本文选用目前业务上常用的 $N D V I$ 方法:

$$
N D V I=\left(\rho_{\text {nir }}-\rho_{\text {red }}\right) /\left(\rho_{\text {nir }}+\rho_{\text {red }}\right)
$$

式中, $\rho_{\text {nir }}$ 为近红外波段反射率, 分别对应于 MODIS 的第 2 通道和 MERSI 的第 4 通道的反射率值, $\rho_{\text {red }}$ 为红光 波段反射率, 分别对应于 MODIS 的第 1 通道和 MERSI 的第 3 通道的反射率值. 蓝藻水华 NDVI 的阈值需根 据观测时刻的大气状况、卫星天顶角并结合目视情况设定, 取值范围为 $-0.15 \sim 0.10^{[20]}$. 本文用 $N D V I$ 法解译 卫星资料得到 2005-2017 年累计 1191 幅太湖蓝藻水华面积 $\geqslant 1 \mathrm{~km}^{2}$ 的卫星遥感影像, 并分别计算得到蓝藻 
水华的时间、面积、频次等信息.

\section{3 太湖蓝藻水华影响程度指数的构建方法}

由于目前尚没有表征蓝藻水华影响程度的客观、统一的指标, 大多以面积来表示, 如累计面积、单次最 大面积和平均面积等 ${ }^{[20]}$, 面积表示了蓝藻水华影响的范围, 而次数多少则可以表示蓝藻水华聚集的频繁程 度, 仅用面积或次数 (如次数很少的大面积蓝藻水华和次数较多的小面积蓝藻水华) 都不能全面、客观地反 映蓝藻水华的影响程度, 为此将面积和次数综合考虑, 设计了蓝藻水华影响程度指数 (Influence degree index of cyanobacteria bloom, 用 $I_{\mathrm{dch}}$ 表示, 简称为蓝藻指数) :

$$
I_{\mathrm{dcb}}=\mathrm{A} \sum_{i=1}^{n} S_{i} / S \times 100 \%+\mathrm{B} \sum_{i=1}^{n} F_{i} / F \times 100 \%
$$

式中, $S_{i}$ 代表历年蓝藻水华面积, $F_{i}$ 代表历年蓝藻水华的次数, $S$ 代表太湖水体的总面积, $F$ 代表蓝藻水华 累计总次数, $A 、 B$ 为权重系数.

采用一种客观的信息量权数法 ${ }^{[33]}$ 来确定公式 (2) 中的权重系数 $\mathrm{A}$ 和 $\mathrm{B}$,这种方法主要根据各评价指标 包含的分辨信息来确定权重系数,具体算法如下.

首先分别计算出蓝藻水华面积序列和蓝藻水华次数序列的变异系数 $C V_{\mathrm{S}}$ 和 $C V_{\mathrm{F}}$, 然后将 $C V_{\mathrm{S}}$ 和 $C V_{\mathrm{F}}$ 作为 面积和次数的权重得分,经归一化处理,即可得到信息量权重系数 $A 、 B$ :

$$
\mathrm{A}=\frac{C V_{\mathrm{S}}}{C V_{\mathrm{S}}+C V_{\mathrm{F}}}, \mathrm{B}=\frac{C V_{\mathrm{F}}}{C V_{\mathrm{S}}+C V_{\mathrm{F}}}\left(C V_{\mathrm{S}}=S_{\mathrm{sd}} / \bar{S}, C V_{\mathrm{F}}=F_{\text {sd }} / \bar{F}\right)
$$

式中, $S_{\mathrm{sd}}$ 代表蓝藻面积的标准差, $\bar{S}$ 代表蓝藻面积的平均值, $F_{\mathrm{sd}}$ 代表蓝藻次数的标准差, $\bar{F}$ 代表蓝藻次数的平 均值.

\section{4 太湖蓝藻水华气象评估模型的构建方法}

1.4.1 通径分析的原理与方法 考虑到气象条件对蓝藻生长和水华形成的影响是综合、复杂的,且各气象因 子的作用也并非等权,为此采用通径分析 (Path coefficient) 方法来分析主要气象因子对蓝藻水华的影响程 度. 通径分析最早是由数量遗传学家休厄尔 - 赖特 (Sewall Wright) 在 1921 年提出来的一种多元统计技 术 $^{[34]}$, 是简单相关分析的延续, 其核心思想是在多元回归的基础上将相关系数加以分解, 通过直接通径和间 接通径系数分别表示某一变量对因变量的直接效应, 以及通过其他变量对因变量的间接效应来反映自变量 与因变量之间的关系.

对于有一个因变量 $y$ 与 $n$ 个自变量 $x_{i}(i=1,2, \cdots, n)$ 的系统, 它们之间存在线性关系, 回归方程为:

$$
y=a_{0}+a_{1} x_{1}+a_{2} x_{2}+\cdots+a_{n} x_{n}
$$

将实际观测值代人公式 (4), 利用最小二乘法解方程组, 因此公式 (4) 通过数学变换, 可以建立正规矩阵 方程:

$$
\left[\begin{array}{cccc}
1 & r_{x_{1} x_{2}} & \cdots & r_{x x_{n}} \\
r_{x_{x} x_{1}} & 1 & \cdots & r_{x_{x} x_{n}} \\
\vdots & \vdots & \ddots & \vdots \\
r_{x_{x} x_{1}} & r_{x_{x} x_{2}} & \cdots & 1
\end{array}\right]\left[\begin{array}{c}
P_{y x_{1}} \\
P_{y x_{2}} \\
\vdots \\
P_{y x_{n}}
\end{array}\right]=\left[\begin{array}{c}
r_{x_{y} y} \\
r_{x_{2} y} \\
\vdots \\
r_{x_{y}, y}
\end{array}\right]
$$

式中, $r_{x x_{i}}$ 为 $x_{i}$ 和 $x_{j}$ 的简单相关系数, $r_{x y}$ 为 $x_{i}$ 和 $y$ 的简单相关系数.

将方程 (5) 求解即可求得通径系数 $P_{y x_{i}}$ :

$$
P_{y x_{i}}=a_{i} \frac{\sigma_{x_{i}}}{\sigma_{y}},(i=1,2, \cdots, n)
$$

式中, $a_{i}$ 即为 $y$ 对 $x_{i}$ 的偏回归系数, $\sigma_{x_{i}} 、 \sigma_{y}$ 分别为 $x_{i} 、 y$ 的标准差, $P_{y x_{i}}$ 表示 $x_{i}$ 对 $y$ 的直接通径系数,而 $x_{i}$ 通 过 $x_{j}$ 对 $y$ 的间接通径系数用 $r_{x x_{j}} P_{y x_{i}}$ 表示, $x_{i}$ 对 $y$ 的决定系数 $D_{(i)}^{2}=P_{y x_{i}}^{2}+2 \sum_{i \neq j} P_{y x_{i}} r_{x x_{j}} P_{y x_{j}}$, 剩余项的通径系数 $P_{y e}=\sqrt{1-\left(r_{x y} P_{y x_{1}}+r_{x, y} P_{y x_{2}}+\cdots+r_{x, y} P_{y x_{n}}\right)}$, 若 $P_{y e}$ 值较大, 则表明误差较大或者还有另外更重要的原因 未考虑在内.

1.4.2 气象评估模型的构建 基于气象观测资料, 分别统计并整理出 2005- 2017 年 $n$ 个气象因子作为自变 
量分别用 $x_{1}, x_{2}, \cdots, x_{n}$ 表示, 蓝藻指数作为因变量用 $y$ 表示.

根据通径分析原理和方法, 首先求出各因子的直接通径系数和间接通径系数, 然后再计算出各因子总 的通径系数, 通过总系数便可求得各气象因子对蓝藻发生程度的影响权重 $\left(C_{i}, i=1,2, \cdots, n\right)$, 其计算方法 如下:

$$
C_{i}=\frac{\left|P_{y x_{i}}+r_{x x_{j}} P_{y x_{i}}\right|}{\sum_{i=1}^{n}\left|P_{y x_{i}}+r_{x x_{j}} P_{y x_{i}}\right|}
$$

根据计算得到的权重系数, 并将气象因子进行归一化处理, 建立太湖蓝藻水华气象评估模型 (Meterological evaluation model of Cyanobacterial Bloom,简称 MMCB) , 用 $I_{\mathrm{mcb}}$ 表示蓝藻水华气象评估指标,则:

$$
I_{\text {meb }}=C_{1} \frac{x_{1}-\min _{x_{1}}}{\max _{x_{1}}-\min _{x_{1}}}+C_{2} \frac{x_{2}-\min _{x_{2}}}{\max _{x_{2}}-\min _{x_{2}}}+\cdots+C_{n} \frac{x_{n}-\min _{x_{e}}}{\max _{x_{n}}-\min _{x_{n}}}
$$

\section{2 结果与分析}

\section{1 蓝藻指数 $I_{\mathrm{dcb}}$ 的构建}

基于遥感反演技术和人工修正,将 2005-2017 年 1191 幅卫星遥感影像分别进行解译,并统计整理得到 2005-2017 年历年蓝藻水华面积和次数, 见表 1.

公式(2)中 $S_{i} / S$ 项中 $S_{i}$ 即为表 1 中历年的蓝藻水华面积, $S$ 为太湖水体面积 (常数: $2445 \mathrm{~km}^{2}$ ),$F_{i} / F$ 项 中 $F_{i}$ 为表 1 中历年的蓝藻水华次数, $F$ 为历年累计次数总和, $\mathrm{A} 、 \mathrm{~B}$ 权重系数根据公式 (3) 计算后, 分别为 $0.65 、 0.35$, 由此计算得到 2005-2017 年 $I_{\mathrm{dcb}}$ 值 (表 1 ). 可以看出, 2007 年的蓝藻指数值最大 $(0.759)$, 其次为 2017 年 (0.709), 相对应的蓝藻水华面积分别为 30337 和 $25273 \mathrm{~km}^{2}$, 远远大于其余年份; 2009 年的蓝藻指数 仅为 0.113 , 是 2005 年以来最小值, 相应的蓝藻水华面积为 $8290 \mathrm{~km}^{2}$, 也为 2005 年以来最小, 且明显小于其 余年份, 表明蓝藻指数 $I_{\mathrm{deb}}$ 与蓝藻水华程度的匹配较为一致,与实际情况基本相符.

表 $12005-2017$ 年太湖蓝藻水华面积和次数统计

Tab.1 Statistics of cyanobacterial bloom area and frequency in Lake Taihu from 2005 to 2017

\begin{tabular}{cccccccccccccc}
\hline 统计因子 & 2005 年 2006 年 2007 年 2008 年 2009 年 2010 年 2011 年 2012 年 2013 年 2014 年 2015 年 2016 年 2017 年 \\
\hline 面积 $/ \mathrm{km}^{2}$ & 11762 & 17608 & 30337 & 14500 & 8290 & 15072 & 10795 & 10093 & 9875 & 9925 & 12843 & 13863 & 25273 \\
次数 & 52 & 55 & 81 & 80 & 82 & 85 & 84 & 91 & 117 & 100 & 104 & 115 & 145 \\
$I_{\mathrm{dcb}}$ & 0.162 & 0.415 & 0.759 & 0.186 & 0.113 & 0.307 & 0.171 & 0.210 & 0.266 & 0.189 & 0.281 & 0.324 & 0.709 \\
\hline
\end{tabular}

\section{2 蓝藻水华气象评估模型的建立}

影响太湖蓝藻生长和水华形成的气象因子包括气温、降水、风速风向和日照等, 选择可能具有影响的气 象因子时, 既考虑年尺度的统计平均值, 如年平均气温、年降水量、年雨日数、年高温日数 (日最高气温》 $35^{\circ} \mathrm{C}$ 的天数)、年日照时数和年平均风速共 6 个年尺度因子, 同时也考虑在蓝藻生长和水华形成主要阶段的 一些影响因子, 如冬、春季节气温对藻类越冬、复苏和微囊藻确立优势会有明显影响, 而梅雨期雨量多少决 定了夏季降水量, 持续大量的降水一方面在短期内会增加蓄水提高水位, 另一方面也会输人较多的营养盐, 共取了 1-2 月平均气温、 $1-3$ 月平均气温、3-5 月平均气温和 6-7 月降水量四个阶段性气象因子. 首先 将上述 10 个气象因子和蓝藻影响程度指数进行 Kolmogorov-Smirnov (K-S) 检验, 结果 $Z$ 值和 $P$ 值均在满足 正态分布条件范围之内, 表明通径分析法适用于该组变量, 然后将这 10 个气象因子作为自变量, 蓝藻影响 程度指数作为因变量进行多元回归, 得到一组自变量的偏回归系数. 由于直接通径系数即为标准化的偏回 归系数, 因此偏回归系数值的正负与直接通径系数值的正负一致, 通过偏回归系数的正负情况即可了解直 接通径系数的正负情况, 由此各判断气象因子对蓝藻水华影响的正负效应, 考察每个气象因子的正负效应 是否与已有研究结果或实际情况相符, 最终选取了年平均气温 $T_{y} 、 1-3$ 月平均气温 $T_{1-3}$ 、年累计降水量 $R_{y}$ 、 6-7 月累计降水量 $R_{6-7}$ 和年平均高温日数 $D_{\operatorname{Tmax}} 5$ 个气象因子纳人模型的构建. 分别统计计算上述 5 个气象 因子作为自变量列于表 2 , 而因变量即为表 1 中的 $I_{\mathrm{deb}}$. 
用 $T_{y} 、 T_{1-3} 、 R_{y} 、 R_{6-7}$ 和 $D_{\text {Tmax }}$ 分别对应自变量 $x_{1}, x_{2}, \cdots, x_{5}$, 与蓝藻指数 $(y)$ 建立回归方程: $y=$ $-5.6021+0.3428 x_{1}+0.0346 x_{2}-0.0001 x_{3}-$ $0.0002 x_{4}-0.0011 x_{5}$. 为了得到公式 $(5)$ 中 $r_{x, x}$ 和 $r_{x y}$ 项, 将 5 个气象因子相互做皮尔逊相关分析, 分 别得到 25 组相关系数列于表 3 , 然后将回归方程 中的偏回归系数和表 3 中相关系数代人方程 (5) 和方程 (6), 解方程可求解出直接通径系数, 最后 再计算出间接通径系数,具体结果见表 4 .

直接通径系数代表自变量对因变量的直接影 响程度,而间接通径系数代表自变量 1 通过自变量 2 对因变量的间接影响程度. 从直接通径系数来 看, $T_{y}$ 和 $T_{1-3}$ 项为正值, 其余项均为负值, 表明 $T_{y}$ 和 $T_{1-3}$ 对蓝藻水华的发生发展具有正效应, 而 $R_{\mathrm{y}}$ 、 $R_{6-7}$ 和 $D_{\text {Tmax }}$ 对蓝藻水华的发生发展具有负效应, 这 与相关文献 ${ }^{[20,35-36]}$ 的研究结果较为一致; 从间接通 径系数来看, 除了 $T_{\mathrm{y}}$ 通过 $T_{1-3}$ 和 $D_{\mathrm{T} \max }$ 来影响蓝藻 水华的间接通径系数较高外,其余间接通径系数 均很小可以忽略不计. 为得到更精确的结果,将间 接通径系数和直接通径系数求和计算出总的通径 系数. 从总通径系数值的绝对值大小来看, 对蓝藻 水华影响程度的大小排序为: $T_{\mathrm{y}}>T_{1-3}>R_{\mathrm{y}}>R_{6-7}>$ $D_{\text {Tmax }}$, 剩余项的通径系数 $P_{y e}$ 为 0.301 , 表明分析误 差较小,方法可行,结果合理. 总通径系数值可以 理解为气象因子对蓝藻水华发生发展程度的影响 权重,由此可以看到, $T_{\mathrm{y}}$ 对蓝藻水华发生发展程度 的影响最大, 而 $D_{\mathrm{T} \text { max }}$ 对蓝藻水华的影响程度最低. 从最近几年的情况看, 2007 和 2017 年平均气温分别为 17.8 和 $17.6^{\circ} \mathrm{C}$, 分别为 2005 年以来最高和次高, 而这两年太湖蓝藻水华的程度也明显偏严重; 而 2013 年全 年高温日数平均为 $47.8 \mathrm{~d}$, 远高于其余年份, 为 $2005-2017$ 年中最多的一年, 其中夏季持续高温, 太湖地区 高温及高温日数创 2005 年以来的极大值, 但这一年的蓝藻水华程度却较轻. 表明上述气象因子影响的权重 与事实基本相符. 根据公式 (7) 计算出各因子对蓝藻水华的影响权重 $C_{i}$, 分别为 $0.653 、 0.183 、 0.072 、 0.067$ 、 0.025 , 从左到右依次为 $T_{y} 、 T_{1-3} 、 R_{\mathrm{y}} 、 R_{6-7}$ 和 $D_{\mathrm{T} \text { max }}$; 考虑气象因子的正负效应, 将 $C_{i}$ 值代人公式 (8) 得到太湖蓝 藻水华气象评估模型:

表 4 各因子通径系数

Tab.4 Path coefficient of each factor

\begin{tabular}{|c|c|c|c|c|c|c|c|}
\hline & \multicolumn{5}{|c|}{ 间接通径系数 } & \multirow{2}{*}{ 直接通径系数 } & \multirow{2}{*}{ 总通径系数 } \\
\hline & $T_{\mathrm{y}}$ & $T_{1-3}$ & $R_{\mathrm{y}}$ & $R_{6-7}$ & $D_{\mathrm{Tmax}}$ & & \\
\hline$T_{\mathrm{y}}$ & & 0.4918 & 0.0522 & -0.0903 & 0.2995 & 0.6888 & 1.4420 \\
\hline$T_{1-3}$ & 0.1316 & & 0.0621 & 0.0178 & 0.0076 & 0.1843 & 0.4034 \\
\hline$R_{\mathrm{y}}$ & -0.0061 & -0.0269 & & -0.0579 & 0.0108 & -0.0800 & -0.1601 \\
\hline$R_{6-7}$ & 0.0144 & -0.0106 & -0.0793 & & 0.0374 & -0.1096 & -0.1478 \\
\hline$D_{\text {Tmax }}$ & -0.0238 & -0.0023 & 0.00074 & 0.0187 & & -0.0548 & -0.0548 \\
\hline
\end{tabular}

Tab.2 Statistics of meteorological factors over years

\begin{tabular}{cccccc}
\hline 时间 & $T_{\mathrm{y}} /{ }^{\circ} \mathrm{C}$ & $T_{1-3} /{ }^{\circ} \mathrm{C}$ & $R_{\mathrm{y}} / \mathrm{mm}$ & $R_{6-7} / \mathrm{mm}$ & $D_{\operatorname{Tmax}} / \mathrm{d}$ \\
\hline 2005 年 & 16.9 & 5.2 & 1006.2 & 194.9 & 20.8 \\
2006 年 & 17.6 & 7.3 & 1088.5 & 324 & 24.2 \\
2007 年 & 17.8 & 8.4 & 1152.2 & 295.6 & 21.8 \\
2008 年 & 16.8 & 5.8 & 1236.3 & 438.6 & 17.2 \\
2009 年 & 17.0 & 7.1 & 1301.5 & 392.9 & 18.8 \\
2010 年 & 16.7 & 6.6 & 1115.6 & 299.8 & 25.8 \\
2011 年 & 16.6 & 5.0 & 1061.2 & 510.7 & 19.2 \\
2012 年 & 16.6 & 5.7 & 1347.2 & 263.6 & 20.2 \\
2013 年 & 17.3 & 6.9 & 1120.8 & 259.5 & 47.8 \\
2014 年 & 16.9 & 7.9 & 1305 & 401.8 & 7.8 \\
2015 年 & 16.9 & 7.6 & 1575.8 & 546.4 & 12.0 \\
2016 年 & 17.4 & 7.3 & 1902.4 & 623.8 & 28.2 \\
2017 年 & 17.6 & 7.8 & 1240.7 & 284.5 & 32.6 \\
\hline
\end{tabular}

表 3 各因子间相关系数统计

Tab.3 Correlation coefficient statistics among various factors

\begin{tabular}{cccccc}
\hline 相关系数 & $T_{\mathrm{y}}$ & $T_{1-3}$ & $R_{\mathrm{y}}$ & $R_{6-7}$ & $D_{\mathrm{T} \max }$ \\
\hline$T_{\mathrm{y}}$ & 1 & 0.714 & 0.758 & -0.131 & 0.435 \\
$T_{1-3}$ & 0.714 & 1 & 0.337 & 0.097 & 0.041 \\
$R_{\mathrm{y}}$ & 0.076 & 0.337 & 1 & 0.724 & -0.135 \\
$R_{6-7}$ & -0.131 & 0.097 & 0.724 & 1 & -0.341 \\
$D_{\mathrm{T} \max }$ & 0.435 & 0.041 & -0.135 & -0.341 & 1 \\
\hline
\end{tabular}




$$
I_{\mathrm{mcb}}=0.653 \frac{x_{1}-\min _{x_{1}}}{\max _{x_{1}}-\min _{x_{1}}}+0.183 \frac{x_{2}-\min _{x_{2}}}{\max _{x_{2}}-\min _{x_{2}}}-0.072 \frac{x_{3}-\min _{x_{3}}}{\max _{x_{3}}-\min _{x_{3}}}-0.067 \frac{x_{4}-\min _{x_{4}}}{\max _{x_{4}}-\min _{x_{4}}}-0.025 \frac{x_{5}-\min _{x_{5}}}{\max _{x_{5}}-\min _{x_{5}}}
$$

根据公式 (9) 可以计算出 $2005-2017$ 历年的综合气象指数, 分别为 $0.195 、 0.658 、 0.824 、 0.111 、 0.289$ 、 $0.130 、-0.033 、 0.01 、 0.465 、 0.282 、 0.210 、 0.407 、 0.668$. 将综合气象指数与蓝藻指数进行皮尔逊相关分析, 相关 系数为 0.826 , 通过了 0.001 显著性检验. 图 1 为根据模型计算得到的综合气象指数与蓝藻指数的拟合曲线, 由图可以看出, 气象指数和蓝藻指数的变化趋势基本一致, 仅 2009、2010 和 2015 年有些小的偏差, 分析其原 因, 可能蓝藻水华的发生发展并非全部由气象因子来主导, 其他因子如水文、水质参数等也会影响蓝藻水华, 营养盐的累积也会对蓝藻生物量的累积产生作用等, 因而导致出现了一些偏差, 尚需要进一步研究这些因素 的综合影响. 注意到 2011 年虽然也监测到有蓝藻水华, 但气象指数却是负值 $(-0.033)$, 这可能跟我们选取的 2005-2017 年的资料序列都有蓝藻水华有关,相对而言这一年的气象条件比较不适宜蓝藻水华的形成.

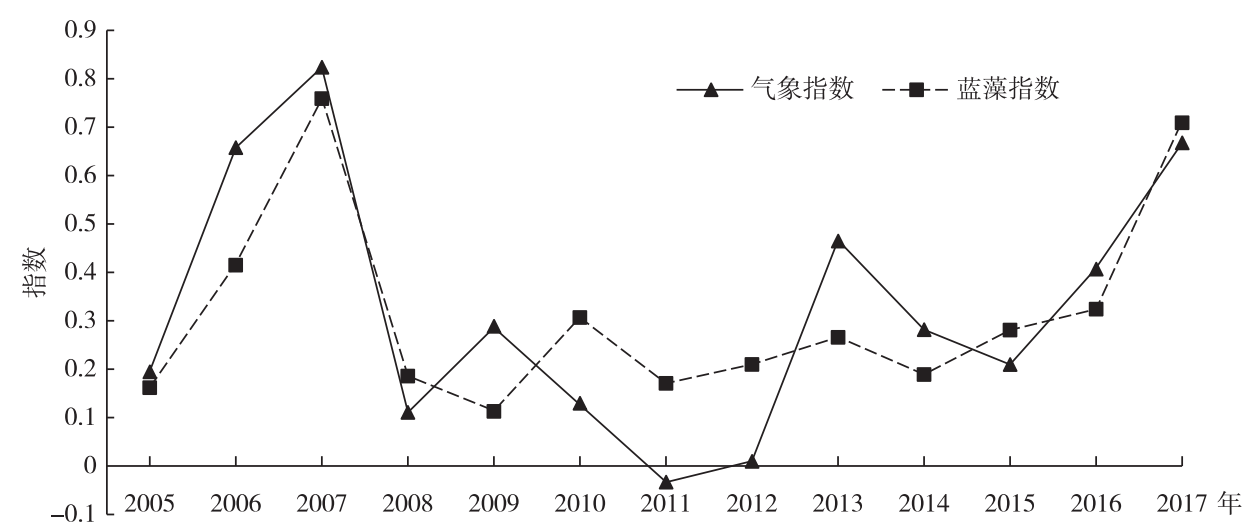

图 $12005-2017$ 年气象指数和蓝藻指数

Fig.1 Meteorological index and cyanobacteria index from 2005 to 2017

根据世界气象组织 (WMO) 推荐的百分位数法 ${ }^{[37]}$ 确定气象指数和蓝藻指数的等级阈值, 将 $2005-2017$ 年的气象指数和蓝藻指数分别以百分位法计算 $25 \%, 75 \%$ 对应的百分位数, 结果气象指数的百分位数为 $0.110 、 0.465$, 蓝藻指数的百分位数为 $0.175 、 0.324$, 分别以此临界值划分气象等级和蓝藻等级, 气象等级由低 到高分为基本适宜、比较适宜、非常适宜, 蓝藻等级由低到高分为轻度、中度和重度, 即气象指数 $\leqslant 0.110$ 为 基本适宜, $0.110<$ 气象指数 $\leqslant 0.465$ 为比较适宜, 气象指数 $>0.465$ 为非常适宜; 蓝藻指数 $\leqslant 0.175$ 为轻度, 0.175 <蓝藻指数 $\leqslant 0.324$ 为中度, 蓝藻指数> 0.324 为重度, 分级结果见表 5 . 蓝藻指数呈重度的分别为 2006 、 2007 和 2017 年共 3 个年份, 与之相对应的气象指数均为非常适宜, 结果完全一致; 蓝藻指数为中度的分别 为 2005、2008、2010 和 2012-2016 年共 8 个年份, 与之相对应的气象指数仅 2012 年偏小一个等级, 其余 7 年均为比较适宜, 与蓝藻指数等级相符; 蓝藻指数为轻度的分别为 2009 和 2011 年, 对应的气象指数分别为 2011 年相符, 2009 年偏大了一个等级, 气象评估模型分类总精度达到了 $84.6 \%$, 其中中度以上的精度达 $90.9 \%$, 表明此模型能够反映综合气象因子与蓝藻水华发生发展程度的关系, 对中度以上表现更好.

\section{3 讨论}

最新研究表明, 在太湖水质富营养化没有根本改变的情况下, 年际之间的水文气象条件差异成为蓝藻 水华暴发强度差异的主控因素, 甚至蓝藻水华受水文气象条件的影响可能会超过营养盐的影响 ${ }^{[6]}$, 因此综 合考虑多气象因子并定量评估这些气象因子的影响, 可以更好地理解环境因子, 尤其是气象因子在蓝藻生 长和水华形成机制中所起的作用, 此外, 利用气象因子的可预测性, 还可以解决太湖蓝藻水华难以监测、无 法防控的问题 ${ }^{[18]}$. 通径分析结果表明, 在 5 个气象因子中, $T_{y}$ 和 $T_{1-3}$ 为正值, 其对蓝藻水华的影响为正效应, 且两者直接通径系数和总系数均位居前列, 表明 $T_{\mathrm{y}}$ 和 $T_{1-3}$ 对蓝藻水华的影响程度较明显. 相关的研究结果 已经证实了气温在蓝藻生长和水华形成中的作用. 商兆堂等 ${ }^{[10]}$ 认为气候变暖的速度加快为太湖蓝藻的生 
表 5 指数等级划分及模型检验

Tab.5 Grade division of indexes and test of model

\begin{tabular}{cccccc}
\hline 时间 & 蓝藻指数 & 蓝藻等级 & 气象指数 & 气象等级 & 模型检验 \\
\hline 2005 年 & 0.162 & 中度 & 0.195 & 比较适宜 & 一致 \\
2006 年 & 0.415 & 重度 & 0.658 & 非常适宜 & 一致 \\
2007 年 & 0.759 & 重度 & 0.824 & 非常适宜 & 一致 \\
2008 年 & 0.186 & 中度 & 0.111 & 比较适宜 & 一致 \\
2009 年 & 0.113 & 轻度 & 0.289 & 比较适宜 & 偏大一个等级 \\
2010 年 & 0.307 & 中度 & 0.130 & 比较适宜 & 一致 \\
2011 年 & 0.171 & 轻度 & -0.033 & 基本适宜 & 一致 \\
2012 年 & 0.210 & 中度 & 0.010 & 比较适宜 & 偏小一个等级 \\
2013 年 & 0.266 & 中度 & 0.465 & 一比较宫 & 一致 \\
2014 年 & 0.189 & 中度 & 0.282 & 比较适宜 & 一致 \\
2015 年 & 0.281 & 中度 & 0.210 & 比较适宜 & 一致 \\
2016 年 & 0.324 & 中度 & 0.407 & 比较适宜 & 一致 \\
2017 年 & 0.709 & 重度 & 0.668 & 非常适宜 & 一致 \\
\hline
\end{tabular}

长发育提供了热量条件, 而年平均气温正是反映此年度冷暖的重要指标, 对蓝藻的生长有直接的作用. 复苏 以后气温不再是蓝藻生长和水华形成的主要限制因子 ${ }^{[20]}$, 但气温是影响太湖蓝藻复苏进程的关键因素之 一 $^{[38]}$, 春季气温越高, 蓝藻从底泥复苏进人水柱并上浮到水面的时间就越早, 谢小萍 等 $^{[35]}$ 研究认为太湖蓝 藻在气温稳定通过 $9^{\circ} \mathrm{C}$ 后开始复苏生长, 太湖地区稳定通过 $9^{\circ} \mathrm{C}$ 的日期平均在 3 月下旬, 因此选择 $1-3$ 月平 均气温可以反映越冬和复苏期气温对太湖蓝藻的影响. 适度偏高的温度对蓝藻水华有促进作用,但高温却 对蓝藻水华具有一定的抑制作用, 王得玉等 ${ }^{[39]}$ 认为大于 $30^{\circ} \mathrm{C}$ 的水温对蓝藻的生长有明显的抑制作用, 文 献 ${ }^{[20]}$ 发现当日平均气温达到 $33^{\circ} \mathrm{C}$ 以上时, 蓝藻水华面积会迅速减小, 因此, 在通径分析中高温日数对蓝藻 水华具有负效应也与上述研究结果相符. 降水对蓝藻水华生消的机制目前尚不十分明晰, 刘心愿等 ${ }^{\left[{ }^{[26]}\right.}$ 认为 降雨过程总是伴随着水华的消退, 而这种抑制作用是阶段性的, 降水过程也会将上游或沿岸泥沙和营养盐 等物质带人湖中, 进而中长期影响蓝藻水华的生消过程, 因此无论是从整体年际尺度的年降水量, 还是从局 部持续大量的梅雨量 (6-7 月降水量), 都会对蓝藻水华的生长和消亡产生影响, 在通径分析结果中都体现 出了负效应. 风场在蓝藻的聚集或水华形成过程中起到重要作用, 就影响单次蓝藻水华的风速来看, Cao 等 ${ }^{[4,22,40]}$ 认为适宜风速范围为 $3 \sim 4 \mathrm{~m} / \mathrm{s}$, 李亚春等 ${ }^{[24]}$ 分析得到前 $1 \mathrm{~h}$ 平均风速 $1.1 \sim 2.9 \mathrm{~m} / \mathrm{s}$ 区间出现大范围 蓝藻水华的占比达 $94 \%$, 而前 $6 \mathrm{~h}$ 平均风速为 $0 \sim 2.0 \mathrm{~m} / \mathrm{s}$ 的占比 $89 \%$,这些研究证实了风对蓝藻水华形成的 重要影响. 但就较长时间尺度如本研究的 1 年时间段内, 由于求算平均值的过程平滑了波动,2005-2017 年 年平均风速为 $2.1 \sim 2.8 \mathrm{~m} / \mathrm{s}$, 均处于适宜大范围蓝藻水华发生的风速范围, 且波动小, 因此模型中没有考虑 风速因子. 至于光照的影响, 孔繁翔等 ${ }^{[11-12]}$ 发现在冬季低光照乃至黑暗环境下蓝藻仍能生存下来, 而在太湖 这样的大型浅水富营养化湖泊, 有学者认为很难用光照调节机制来解释蓝藻水华的快速出现与消散 ${ }^{[18]}$, 张 海春等 ${ }^{[21]}$ 在水柱实验中证明, 在无光照和光照度为 $5000 \mathrm{~lx}$ 的条件下, 铜绿微囊藻都会出现明显的表面浮 聚现象; 张晓忆等 ${ }^{\left[{ }^{[36}\right.}$ 认为日照时数与蓝藻水华无显著相关关系; 武胜利等 ${ }^{[41]}$ 发现在阴天状况下也能观测到 大面积蓝藻水华, 在日常工作中我们也有类似发现, 所以认为光照虽然是蓝藻光合作用不可缺少的, 但即使 在阴天条件下光照也能满足蓝藻的光合作用. 此外, 由于日照时数与降水量之间存在一定的关系, 因而降水 量也可以一定程度反映光照的影响, 因此, 模型中没有纳人光照因子, 并非否认其对蓝藻生长和水华的影响.

充足的营养盐是太湖蓝藻水华形成的基础条件, 很多学者都证实了氮、磷等营养盐与藻类生长的关 系 ${ }^{[42]}$. 但不同的观测方法、不同的观测区域,其营养盐观测和分析结果会有明显差异 ${ }^{[43-44]}$, 朱广伟等 ${ }^{[6]}$ 分析 得到太湖北部区域总氮浓度自 2006 年达峰值后持续下降至 2017 年, 总磷浓度呈双峰状, 峰值分别出现在 2006 年和 2017 年; 而戴秀丽等 ${ }^{[45]}$ 分析认为太湖全湖氮、磷浓度自 2007 年开始持续下降至 2015 年，而 2007 年以来卫星观测到的蓝藻水华面积和次数却下降趋势不明显, 因此, 在太湖水质维持富营养化的前提 
下, 营养盐浓度的增减对蓝藻生物量的累积作用可能并不十分明显, 而水文气象条件的作用却可能更加突 出, 其机理还需要更深人的研究, 因此, 综合营养盐浓度累积与环境因子来研究蓝藻水华的发生发展机理应 是未来研究的方向之一.

\section{4 结论}

1 ) 根据蓝藻水华面积和次数构建的太湖蓝藻影响程度指数 $I_{\mathrm{dcb}}$, 与历年蓝藻水华程度的实际情况基本 相符, 能够客观地反映太湖蓝藻水华的发生发展程度.

2) $T_{\mathrm{y}}$ 和 $T_{1-3}$ 对蓝藻水华的发生发展具有正效应, 而 $R_{\mathrm{y}} 、 R_{6-7}$ 和 $D_{\mathrm{T} \max }$ 具有负效应; 各气象因子对太湖蓝藻 水华影响程度的权重排序为: $T_{\mathrm{y}}>T_{1-3}>R_{\mathrm{y}}>R_{6-7}>D_{\mathrm{T} \max }$.

3 ) 太湖蓝藻水华气象评估模型的等级分类总精度达 $84.6 \%$, 其中中度以上达 $90.9 \%$,模型能够较好地反 映综合气象因子与蓝藻水华发生发展程度的关系, 对中度以上表现更好, 表明模型可用于定量评估气象条 件对蓝藻水华的综合影响.

4) 模型使用的观测数据是在太湖水质维持富营养化的前提下获取的,因此, 模型有可能突出了气象条 件的作用, 而没有体现出营养盐浓度的增减对蓝藻生物量累积的效应. 需要综合分析营养盐浓度累积与环 境因子对蓝藻水华发生发展的影响,进一步提高模型的适应性和精度,这也是我们未来努力的方向.

\section{5 参考文献}

[ 1 ] Qin BQ, Gao G, Zhu GW et al. Eutrophication and response of its ecological system. Chinese Science Bulletin, 2013,58 (10) : 855-864. DOI : 10.1360/csb2013-58-10-855. [秦伯强, 高光, 朱广伟等. 湖泊富营养化及其生态系统响应. 科学通报, 2013, 58(10): 855-864.]

[ 2 ] Wang CL, Pan WY, Han YQ et al. Effect of global climate change on cyanobacteria bloom in Lake Taihu. China Environmental Science, 2010, 30(6) : 822-828. [王成林, 潘维玉, 韩月其等. 全球气候变化对太湖蓝藻水华发展演变的影 响. 中国环境科学, 2010, 30(6): 822-828.]

[ 3 ] Hai X. Nitrogen and phosphorus inputs control phytoplankton growth in eutrophic Lake Taihu, China. Limnology and Oceanography, 2010, 55(1): 420-432.

[ 4 ] Cao HS, Tao Yi, Kong FX. Relationship between temperature and cyanobacterial recruitment from sediment in laboratory and field studies. Journal of Freshwater Ecology, 2008, 23(3) : 405-412.

[ 5 ] Qin BQ, Wang XD, Tang XM et al. Drinking water crisis caused by eutrophication and cyanobacterial bloom in Lake Taihu: Cause and measurement. Advances in Earth Science, 2007, 22(9):896-906. [秦伯强, 王小冬, 汤祥明等. 太 湖富营养化与蓝藻水华引起的饮用水危机一一原因与对策. 地球科学进展, 2007, 22(9) : 896-906. ]

[ 6 ] Zhu GW, Qin BQ, Zhang YL et al. Variation and driving factors of nutrients and chlorophyll-a concentrations in northern region of Lake Taihu, China, 2005-2017. J Lake Sci, 2018, 30(2) : 279-295. DOI:10.18307/2018.0201. [朱广伟, 秦 伯强, 张运林等. 2005-2017 年北部太湖水体叶绿素 a 和营养盐变化及影响因素. 湖泊科学, 2018, 30(2): 279-295. ]

[ 7 ] O'Neila JM, Davisb TW, Burfordb MA et al. The rise of harmful cyanobacteria blooms: The potential roles of eutrophication and climate change. Harmful Algae, 2012, 14: 313-334.

[ 8 ] Te SH, Chen EY, Gin KY. Comparison of quantitative PCR and droplet digital PCR multiplex assays for two genera of bloomforming cyanobacteria, Cylindrospermopsis and Microcystis. Appl Environ Microbiol, 2015, 81(15) : 5203-5211.

[ 9 ] Rigosi A, Carey CC, Ibelings BW et al. The interaction between climate warming and eutrophication to promote cyanobacteria is dependent on trophic state and varies among taxa. Limnology and Oceanography, 2014, 59(1) : 99-114.

[10] Shang ZT, Ren J, Qin MR et al. Relationships between climatic change and cyanobacterial bloom in Lake Taihu. Chinese Journal of Ecology, 2010, 29(1) : 55-56. [商兆堂, 任健, 秦铭荣. 气候变化与太湖蓝藻暴发的关系. 生态学杂志, 2010, 29(1): 55-56.]

[11] Kong FX, Gao G. Hypothesis on cyanobacteria bloom-forming mechanism in large shallow eutrophic lakes. Acta Ecologica Sinica, 2005, 25(3) : 589-595. [孔繁翔, 高光. 大型浅水富营养化湖泊中蓝藻水华形成机理的思考. 生态学报, $2005,25(3): 589-595$. ]

[12] Kong FX, Ma RH, Gao JF et al. The theory and practice of prevention, forecast and warning on cyanobacteria bloom in 
Lake Taihu. J Lake Sci, 2009, 21(3) : 314-328. DOI: 10.18307/2009.0302. [ 繁翔, 马荣华, 高俊峰等. 太湖蓝藻 水华的预防、预测和预警的理论与实践. 湖泊科学, 2009, 21(3):314-328.]

[13] Zhang M, Duan HT, Shi XL et al. Contributions of meteorology to the phenology of cyanobacterial blooms: Implications for future climate change. Water Research, 2012, 46(2): 442-452.

[14] Wu TF, Qin BQ, Zhu GW et al. Dynamics of cyanobacteria bloom formation during short-term hydrodynamic fluctuation in a large shallow, eutrophic, and wind-exposed Lake Taihu, China. Environmental Science and Pollution Research, 2013, 20 ( 12 ) : 8546-8556.

[15] Reichwaldt ES, Ghadouani A. Effects of rainfall patterns on toxic cyanobacterial blooms in a changing climate: between simplistic scenarios and complex dynamics. Water Research, 2011, 46(5) :1372-1393.

[16] Wu J, Chen XC, Kong HN et al. The effect of light intensity on the cell density and chain length of Anabaena flos-aquae. China Environmental Sciencece, 2012, 32(5): 875-879. [巫娟, 陈雪初, 孔海南等. 光照度对水华鱼腥藻细胞比重 与藻丝长度的影响研究. 中国环境科学, 2012, 32(5) : 875-879.]

[17] Wu TF, Zhu GW, Qin BQ et al. Prior wind field induced hydrodynamics and its influence on cyanobacterial bloom in northern bays of Lake Taihu, China. J Lake Sci, 2012, 24(3) : 409-415. DOI:10.18307/2012.0312 [吴挺峰, 朱广伟, 秦伯强等.前期风场控制的太湖北部湖湾水动力及对蓝藻水华影响. 湖泊科学, 2012, 24(3): 409-415.]

[18] Qin BQ, Yang GJ, MA JR et al. Dynamics of variability and mechanism of harmful cyanobacteria bloom in Lake Taihu, China. Chinese Science Bulletin, 2016, 61(7) : 759-770. [秦伯强，杨桂军，马建荣等. 太湖蓝藻水华“暴发” 的动态 特征及其机制. 科学通报, 2016, 61(7): 759-770.]

[19] Deng J, Qin BQ, Paerl HW et al. Earlier and warmer springs increase cyanobacterial (Microcystis spp.) blooms in subtropical Lake Taihu, China. Freshwater Biol, 2014, 59: 1076-1085.

[20] Li YC, Xie XP, Zhu XL et al. Applying remote sensing techniques in analysis of temperature features causing cyanobacteria bloom in Lake Taihu. J Lake Sci, 2016, 28(6) : 1256-1264. DOI:10.18307/2016.0611. [李亚春, 谢小萍, 朱小莉 等. 结合卫星遥感技术的太湖蓝藻水华形成温度特征分析. 湖泊科学, 2016, 28(6): 1256-1264.]

[21] Zhang HC, Chen XC, Li CJ. The effect of light intensity on cyanophytes vertical distribution. Environmental Pollution and Control, 2010, 32 (5) : 64-67. [张海春, 陈雪初, 李春杰. 光照度对蓝藻垂直迁移特性影响研究. 环境污染与防 治, 2010, 32(5) : 64-67.]

[22] Wang CL, Huang Juan, Qian Xin. Spatio-temporal characteristics of wind field under high temperature and gentle breeze in Taihu Basin. J Lake Sci, 2011, 23(1) : 122-128. DOI:10.18307/2011.0118. [王成林, 黄娟, 钱新. 高温微风条件下 太湖流域风场时空特征分析. 湖泊科学, 2011, 23(1): 122-128.]

[23] Webster I, Hutchinson PA. Effect of wind on the distribution of phytoplankton cells in lakes revisited. Limnology and Oceanography, 1994, 39: 365-373.

[24] Li YC, Xie XP, Hang X et al. Analysis of wind field features causing cyanobacteria bloom in Lake Taihu combined with remote sensing methods. China Environmental Science, 2016, 36(2) : 525-533. [李亚春, 谢小萍, 杭釒等. 结合卫星 遥感技术的太湖蓝藻水华形成风场特征. 中国环境科学, 2016, 36(2):525-533.]

[25] Lu WK, Yu LX, Ou XK et al. Relationship between occurrence frequency of cyanobacteria bloom and meteorological factors in Lake Dianchi. J Lake Sci, 2017, 29(3) : 534-545. DOI: 10.18307/2017.0302. [鲁韦坤, 余凌翔, 欧晓昆等. 滇 池蓝藻水华发生频率与气象因子的关系. 湖泊科学, 2017, 29(3) : 534-545.]

[26] Liu XY, Song LX, Ji DB et al. Effect of the rainfall on extinction of cyanobacteria bloom and its mechanism analysis. Environmental Science, 2018, 39(2): 774-782. [刘心愿, 宋林旭, 纪道斌等. 降雨对蓝藻水华消退影响及其机制分析. 环境科学, 2018, 39(2): 774-782.]

[27] Zhang X, Zou LY. Study advances on technology of nutrient control in lake water Body. Environmental Science and Technology, 2009, 22(4): 60-64. [詹旭, 邹路易. 湖泊水体中营养盐控制技术研究进展. 环境科技, 2009, 22(4)： 60-64. ]

[28] Zhao MX, Han BP. Analysis of factors affecting cyanobacteria bloom in a tropical reservoir (Tangxi Reservoir, China). Acta Ecologica Sinica, 2005, 25(7): 1554-1561. [赵孟绪, 韩博平. 汤溪水库蓝藻水华发生的影响因子分析. 生态学 报, 2005, 25(7): 1554-1561.]

[29] Duan HT, Zhang SX, Zhang YZ. Cyanobacteria bloom monitoring with remote sensing in Lake Taihu. J Lake Sci, 2008, 20(2) : 145-152. DOI: 10.18307/2008.0202. [段洪涛, 张寿选, 张渊智. 太湖蓝藻水华遥感监测方法. 湖泊科学, 
$2008, \mathbf{2 0}(2): 145-152$.

[30] Ma RH, Kong WJ, Duan HT et al. Quantitative estimation of phycocyanin concentration using MODIS imagery during the period of cyanobacterial blooming in Lake Taihu. China Environmental Sciencece, 2009, 29(3) : 254-260. [马荣华, 孔 维娟, 段洪涛等. 基于 MODIS 影像估测太湖蓝藻暴发期藻蓝素含量. 中国环境科学, 2009, 29(3) : 254-260.]

[31] Han XZ, Wu CY, Zheng W et al. Satellite remote sensing of cyanophyte using observed spectral measurements over the Lake Taihu. Journal of Applied Meteorological Science, 2010, 21(6): 724-731. [韩秀珍, 吴朝阳, 郑伟等. 基于水面实 测光谱的太湖蓝藻卫星遥感研究. 应用气象学报, 2010, 21(6): 724-731.]

[32] Hu CM, Lee ZP, Ma RH et al. Moderate Resolution Imaging Spectroradiometer (MODIS) observations of cyanobacteria blooms in Lake Taihu, China. Journal of Geophysical Research, 2010, 115(C04002) : 1-20.

[33] Zeng XB. Statistical weight theory[Dissertation]. Dalian: Dongbei University of Finance and Economics, 1998. [曾宪报. 统计权数论 [学位论文]. 大连: 东北财经大学, 1998.]

[34] Song XY, Zhu ZY, Liu YW et al. Application of path analysis in stepwise linear regression SPSS. Arid Zone Research, 2016, 33(1) : 108-113. DOI: 10.13866/j.azr.2016.01.13. [宋小园, 朱仲元, 刘艳伟等. 通径分析在 SPSS 逐步线性 回归中的实现. 干旱区研究, 2016, 33(1) : 108-113.]

[ 35] Xie XP, Li YC, Hang Xin et al. The effect of air temperature on the process of cyanobacteria recruitment and dormancy in Lake Taihu. J Lake Sci, 2016, 28(4) : 818-824. DOI:10.18307/2016.0415. [谢小萍, 李亚春, 杭金等. 气温对太湖 蓝藻复苏和休眠进程的影响. 湖泊科学, 2016, 28(4) : 818-824.]

[36] Zhang XY, Jing YS, Chen Fei et al. Effect and forecast of weather conditions on cyanobacterial bloom outbreaks based on RDALR model in Lake Taihu, China. Chinese Journal of Environmental Engineering, 2016, 10(10) : 5722-5729. DOI: 10.12030/j.cjee.201504022. [张晓忆, 景元书, 陈飞等. 基于 RDALR 模型分析气象条件对太湖蓝藻水华发生的影 响及预报. 环境工程学报, 2016, 10(10): 5722-5729.]

[37] Xu M, Zhang P, Gao P et al. The long-term prediction method of rice annual agricultural climate status in jiangsu province based on climatic suitability. Meteor Mon, 2018, 44(9): 1220-1227. [徐敏, 张佩, 高苹等. 基于气候适宜度的江苏 水稻气候年景预测方法. 气象, 2018, 44(9): 1220-1227.]

[38] Wu XD, Kong FX. The determination of in situ growth rates of the bloomed Microcystis in Meiliang Bay, Lake Taihu. China Environmental Science, 2008, 28(6): 552-555. [ 吴晓东, 孔繁翔. 水华期间太湖梅梁湾微囊藻原位生长速率的 测定. 中国环境科学, 2008, 28(6): 552-555.]

[39] Wang DY, Feng XZ, Zhou LG et al. Relationship between blue algal bloom and water temperature in Lake Taihu based on MODIS. J Lake Sci, 2008, 20(2) : 173-178. DOI: 10.18307/2008.0206. [王得玉, 冯学智, 周立国等. 太湖蓝藻爆发 与水温的关系的 MODIS 遥感. 湖泊科学, 2008, 20(2) : 173-178.]

[40] Sun XP, Qin BQ, Zhu GW et al. Effect of wind-induced wave on concentration of colloidal nutrient and phytoplankton in Lake Taihu. Chinese Journal of Environmental Science, 2007, 28(3): 506-511. [孙小静, 秦伯强, 朱广伟等. 风浪对 太湖水体中胶体态营养盐和浮游植物的影响. 环境科学, 2007, 28(3): 506-511.]

[41] Wu SL, Liu C, Sun J et al. Remote sensing and analysis on meteorological factors of blue algal bloom in Lake Taihu. Meteor Mon, 2009, 35(1) : 18-23. [武胜利, 刘诚, 孙军等. 卫星遥感太湖蓝藻水华分布及其气象影响要素分析. 气象, $2009, \mathbf{3 5}(1): 18-23$. ]

[42] Xiong W, Qian X, Ye R et al. Eco-model based analysis of Lake Taihu cyanobacteria growth factors. J Lake Sci, 2012,24 (5) : 698-704. DOI: 10.18307/2012.0509. [ 熊文, 钱新, 叶瑞等. 基于生态模型的太湖蓝藻生长因子解析. 湖泊科 学, 2012, 24(5): 698-704.]

[43] Zhu W, Tan YQ, Wang RC et al. The trend of water quality variation and analysis in typical area of Lake Taihu, 20102017. J Lake Sci, 2018, 30(2) : 296-305. DOI: 10.18307/2018.0202. [ 朱伟, 谈永琴, 王若辰等. 太湖典型区 20102017 年间水质变化趋势及异常分析. 湖泊科学, 2018, 30(2) : 296-305.]

[44] Ma Q, Tian W, Wu ZM. Total phosphorus and total nitrogen concentrations of the water diverted from Yangtze River to Lake Taihu through Wangyu River. J Lake Sci, 2014, 26(2) : 207-212. DOI: 10.18307/2014.0206. [马倩, 田威, 吴朝 明. 望虞河引长江水人太湖水体的总磷、总氮分析. 湖泊科学, 2014, 26(2) : 207-212.]

[45] Dai XL, Qian PQ, Ye L et al. Changes in nitrogen and phosphorus concentrations in Lake Taihu, 1985-2015. J Lake Sci, 2016, 28(5) : 935-943. DOI: 10.18307/2016.0502. [戴秀丽, 钱佩琪, 叶凉等. 太湖水体氮、磷浓度演变趋势 (1985-2015 年). 湖泊科学, 2016, 28(5) : 935-943.] 